Article

\title{
Osteogenic Properties of Novel Methylsulfonylmethane-Coated Hydroxyapatite Scaffold
}

\author{
Jeong-Hyun Ryu ${ }^{1}$, Tae-Yun Kang ${ }^{1,2}{ }^{\text {, Hyunjung Shin }}{ }^{3}{ }^{\mathbb{D}}$, Kwang-Mahn Kim ${ }^{1,2}$, \\ Min-Ho Hong ${ }^{3, *(D)}$ and Jae-Sung Kwon $1,2, *$ (D) \\ 1 Department and Research Institute of Dental Biomaterials and Bioengineering, \\ Yonsei University College of Dentistry, Seoul 03722, Korea; sweetden623@gmail.com (J.-H.R.); \\ tykang@yuhs.ac (T.-Y.K.); kmkim@yuhs.ac (K.-M.K.) \\ 2 BK21 PLUS Project, Yonsei University College of Dentistry, Seoul 03722, Korea \\ 3 Nature Inspired Materials Processing Research Center, Department of Energy Science, \\ Sungkyunkwan University, Suwon 16419, Korea; hshin@skku.edu \\ * Correspondence: mhong@skku.edu (M.-H.H.); jkwon@yuhs.ac (J.-S.K.); \\ Tel.: +82-31-299-4266 (M.-H.H.); +82-2-2228-8301 (J.-S.K.)
}

Received: 28 October 2020; Accepted: 9 November 2020; Published: 12 November 2020

\begin{abstract}
Despite numerous advantages of using porous hydroxyapatite (HAp) scaffolds in bone regeneration, the material is limited in terms of osteoinduction. In this study, the porous scaffold made from nanosized HAp was coated with different concentrations of osteoinductive aqueous methylsulfonylmethane (MSM) solution $(2.5,5,10$, and 20\%) and the corresponding MH scaffolds were referred to as $\mathrm{MH} 2.5, \mathrm{MH}$, $\mathrm{MH10}$, and $\mathrm{MH20}$, respectively. The results showed that all $\mathrm{MH}$ scaffolds resulted in burst release of MSM for up to $7 \mathrm{~d}$. Cellular experiments were conducted using MC3T3-E1 preosteoblast cells, which showed no significant difference between the MH2.5 scaffold and the control with respect to the rate of cell proliferation $(p>0.05)$. There was no significant difference between each group at day 4 for alkaline phosphatase (ALP) activity, though the MH2.5 group showed higher level of activity than other groups at day 10. Calcium deposition, using alizarin red staining, showed that cell mineralization was significantly higher in the MH2.5 scaffold than that in the HAp scaffold $(p<0.0001)$. This study indicated that the MH2.5 scaffold has potential for both osteoinduction and osteoconduction in bone regeneration.
\end{abstract}

Keywords: methylsulfonylmethane; hydroxyapatite; scaffold; osteoinduction

\section{Introduction}

The regeneration of tissue in large bone defects requiring oral, craniofacial, or orthopedic surgery is limited and remains a substantial therapeutic challenge [1]. The use of autologous bone grafts for bone regeneration has been the gold standard, given its strong osteogenic potential [2]. However, the supply of autologous bones to patients with damaged bones is limited [3]. Thus, the development of bone substitute materials, such as hydroxyapatite (HAp), $\beta$-tricalcium phosphate, and biphasic calcium phosphate, for bone regeneration has been proven to be efficient [4].

Studies have shown that HAp is the main inorganic mineral component of bone and teeth $[5,6]$. Hydroxyapatite has good biocompatibility and osteoconduction ability as an artificial bone substitute material [7,8]. In addition, the material allows adhesion of bone cells and cell proliferation [9]. However, despite its excellent osteoconductive properties, HAp has limited application owing to weak osteoinduction $[10,11]$. 
Methylsulfonylmethane (MSM, $\mathrm{C}_{2} \mathrm{H}_{6} \mathrm{O}_{2} \mathrm{~S}$ ), also known as dimethyl sulfone, is an organic sulfur molecule. MSM is a naturally derived sulfur compound found in many plants and food sources $[12,13]$. It is non-toxic, has anti-inflammatory activity, and has been shown to prevent osteoarthritis. Recently, it was shown that MSM could promote osteogenic differentiation of mesenchymal stem cells (MSCs) $[14,15]$. Kim et al. showed that MSM increases the expression of bone morphogenetic protein 2 (BMP-2) to induce the differentiation of MSCs into osteoblasts [16]. This indicated that MSM might have the ability to induce osteogenic differentiation. Although MSM was well known in osteogenic differentiation, there has only been a few reports for the application of MSM in the biomedical field, such as bone tissue engineering and regenerative medicine.

Dip-coating is the simplest technique that does not require substantial machinery and equipment [17]. In this method, the porous scaffold is dipped into the coating solution containing a specific drug-like chemical that would allow the ceramic scaffold to act as a carrier for the drug delivery system [18-20]. Many studies have demonstrated that scaffolds coated with the drug solution using the dip-coating technique are effective for bone tissue engineering [21-23].

Therefore, in this study, an MSM aqueous solution coated on the HAp scaffold (MH) was successfully fabricated by the sponge replica and dip-coating method. This study was based on the hypothesis that the MH scaffold will induce considerable osteoblast proliferation and differentiation with respect to the control HAp scaffold.

\section{Materials and Methods}

\subsection{Materials}

Nano sized HAp powder was purchased from Ossgen (Daegu, Korea). Polyvinyl butyral (PVB) and MSM purchased from Sigma-Aldrich (St. Louis, MO, USA) were used. Polyvinylidene difluoride membranes obtained from Millipore (Schwalbach, Germany) were used. 3-(4,5-Dimethylthiazol-2yl)-2,5-diphenyltetrazolum bromide (MTT) and alizarin red S purchased from Sigma-Aldrich (St. Louis, MO, USA) were used. All chemicals and reagents were used as received without further purification unless otherwise noted.

\subsection{HAp Scaffold Preparation}

The hydroxyapatite scaffold was prepared in accordance with the method described previously [11]. In brief, $5 \%(w / v)$ PVB in a solution (binder) of absolute ethanol was vigorously stirred for $2 \mathrm{~h}$ and added to $55 \%(w / v)$ HAp solution. The mixture was vigorously stirred for an additional $24 \mathrm{~h}$. Polyurethane (PU) foam templates were punched to form a three-dimensional cylindrical shape (diameter, $7 \mathrm{~mm}$; height, $9 \mathrm{~mm}$ ) and immersed in the HAp slurry. In order to make the porous scaffold, the slurry was dispersed constantly and the blocked pores were removed using an air gun. The sponge-coated HAp slurry was then dried at $90^{\circ} \mathrm{C}$ for $30 \mathrm{~min}$. These dipping and drying steps were repeated twice. The sponge-coated HAp slurry was heated to $600^{\circ} \mathrm{C}$ at a heating velocity of $5^{\circ} \mathrm{C} / \mathrm{min}$ for $1 \mathrm{~h}$ in order to burn out the sponge and binder. Finally, the sample was sintered to $1250{ }^{\circ} \mathrm{C}$ for $3 \mathrm{~h}$ at a heating velocity of $5{ }^{\circ} \mathrm{C} / \mathrm{min}$ using a furnace (Lindberg/MPH, Riverside, MI, USA).

\subsection{MH Scaffolds Preparation}

Hydroxyapatite scaffolds were coated with MSM by the dip-coating/vacuum storage method, in accordance with the method described previously [24,25]. MSM-coated samples were stored in a vacuum chamber for $24 \mathrm{~h}$, followed by drying at $60^{\circ} \mathrm{C}$ overnight in a dry oven. The drying temperature was fixed based on the melting point of MSM, which has been previously described [26]. The concentration of methylsulfonylmethane used in the dip-coating process differed depending on the experimental groups, which included $2.5,5,10$, and 20\% $(w / v)$ solutions prepared by dissolving MSM into distilled water (Table 1). 
Table 1. Methylsulfonylmethane concentrations used for the control and experimental groups.

\begin{tabular}{cccccc}
\hline MSM Concentration $(w / v)$ & $0 \%$ & $2.5 \%$ & $5.0 \%$ & $10.0 \%$ & $20.0 \%$ \\
Group Code & HAp & MH2.5 & MH5 & MH10 & MH20 \\
\hline
\end{tabular}

\subsection{Scanning Electron Microscopy Observation}

The morphological characteristics of the scaffolds were observed by scanning electron microscopy (SEM; MERLIN, Carl Zeiss AG, Oberkochen, Germany) at an accelerating voltage of $15 \mathrm{kV}$, after sputter coating with carbon. In addition, an elemental mapping analysis was performed by energy dispersive spectroscopy (XFlash 6130, Bruker, Berlin, Germany) on the elemental composition of the scaffolds.

\subsection{In Vitro Sulphur Ion Release}

The in vitro release of MSM from MH scaffolds was considered by the method adapted from previously published literature [27]. Both HAp and MH scaffolds were immersed in $10 \mathrm{~mL}$ of phosphate-buffered saline (PBS) and incubated for $14 \mathrm{~d}$. PBS was then removed and filtered (pore size, $0.2 \mu \mathrm{m})$. Sulfur ion levels were determined using an inductively coupled plasma-optical emission spectrophotometer (ICP-OES; iCAP7400, Thermo Fisher Scientific, Waltham, MA, USA), and the ions were considered to be an indicator for MSM.

\subsection{Cell Subculture}

MC3T3-E1 osteoblastic cells (CRL-2593, subclone 4) from mouse calvaria obtained from the American Type Culture Collection (Manassas, VA, USA) were used, which were cultured in alpha minimum essential medium ( $\alpha$-MEM; Welgene, Gyeongsan, Korea). Each culture medium consisted of $10 \%$ fetal bovine serum (FBS; Gibco, Grand Island, NY, USA) and 1\% antibiotic/antimycotic mix and the completed culture medium was changed every 2 to $3 \mathrm{~d}$. Furthermore, the osteogenic medium was induced by the addition of $50 \mu \mathrm{g} / \mathrm{mL}$ ascorbic acid, $10 \mathrm{mM} \beta$-glycerophosphate, and $100 \mathrm{nM}$ dexamethasone. The osteogenic medium was subsequently replaced every $2 \mathrm{~d}$.

\subsection{Cell Proliferation}

MC3T3-E1 cells were seeded at a density of $1 \times 10^{5}$ cells per scaffold (in a 24-well culture plate) and cultured for 3 days. Cell proliferation was quantitatively analyzed using the MTT $(1 \mathrm{mg} / \mathrm{mL})$ assay in accordance with the method described in a previous study [28]. Briefly, cells cultured on the 24-well culture plate were exposed to test and control materials indirectly as the materials were placed in a cell insert, so that extractants from the materials would be in contact with the cells. The optical density (O.D) was measured at $570 \mathrm{~nm}$ using a microplate spectrophotometer (Epoch, Bio-Tek, Seoul, Korea). The cell proliferation was calculated as follows:

$$
\text { Cell proliferation rate }(\%)=[\text { O.D }]_{\text {day } 3}-[\text { O.D }]_{\text {day }} 1 /[\text { O.D }]_{\text {day } 1} \times 100
$$

\subsection{Alkaline Phosphatase (ALP) Activity}

To evaluate ALP activity, the indirect method described in the cell proliferation method was applied in accordance with a previous study [28]. The test was performed for 4 and 10 days to demonstrate the initial step of osteogenic differentiation. ALP activity was measured by using a SensoLyte para-Nitrophenylphosphate (pNPP) alkaline phosphatase assay kit (Anaspec, San Jose, CA, USA) in accordance with the manufacturer's protocol. The total protein content was measured by using a Pierce bicinchoninic acid assay kit (Thermo Fischer Scientific, Waltham, MA, USA) following the manufacturer's protocol. 


\subsection{Mineralization}

To evaluate mineralization, the indirect method described in the cell proliferation method was applied in accordance with a previous study [28]. The deposition of calcium at day 14 from the osteoblast-like cells was considered by alizarin red staining, in accordance with the method described earlier [11]. In brief, cells were cultured, attached to the cell culture plate, rinsed with PBS, and fixed in $70 \% \mathrm{EtOH}$ at $4{ }^{\circ} \mathrm{C}$ for $1 \mathrm{~h}$. The fixed cells were then stained with $40 \mathrm{mM}$ alizarin red (pH 4.2) by incubating with the solution for $10 \mathrm{~min}$ at room temperature. Plates were washed with deionized water until the point where the dye's colour disappears. The residual stain with $10 \%$ cetylpyridinium chloride was eluted and the optical density of this solution was measured at $562 \mathrm{~nm}$ using a microplate spectrophotometer (Epoch, Bio-Tek, Seoul, Korea).

\subsection{Statistical Analysis}

The graphical data are presented as mean \pm standard deviation. Experimental data of the in vitro test were analyzed statistically by one-way analysis of variance with Tukey's post-hoc tests (SPSS23, Chicago, IL, USA). The statistical significance was set at a $p$ value $<0.05$.

\section{Results}

\subsection{Characterization of HAp and MH Scaffold}

The surface morphology and structure of HAp and MH groups observed using scanning electron microscopy (SEM) are shown in Figure 1. The macroporous structures of HAp scaffolds showed a degree of interconnectivity, which is a characteristic feature of porous scaffolds formed by the sponge replica method [29]. The SEM images in the HAp group showed a preserved microporous structure and indicated the presence of $\mathrm{Ca}$ and $\mathrm{P}$. However, $\mathrm{MH}$ groups indicated $\mathrm{Ca}, \mathrm{P}$, and $\mathrm{S}$. We confirmed that the MH groups were successfully coated with the aqueous MSM solution in the HAp group.



Figure 1. Surface morphology (left) and chemical elements (right) of porous hydroxyapatite (HAp) and $\mathrm{MH}$ groups. Element mapping analyses were performed for calcium, phosphorous, and sulfur. Low magnification $(100 \times)$ images: scale bar is $200 \mu \mathrm{m}$, high magnification $(1000 \times)$ images: scale bar is $10 \mu \mathrm{m}$. 


\subsection{Sulphur Ion Release Test}

The release curves of MH scaffolds in phosphate-buffered saline (PBS) are shown in Figure 2. There was an initial burst release of sulfur ions in MSM for MH10 and MH20 groups at day 1, which was significantly greater than that observed in case of MH2.5 and MH5 groups $(p<0.0001)$. All the groups showed constant release of MSM until day 7. No sulfur ions in MSM were detected on day 21.
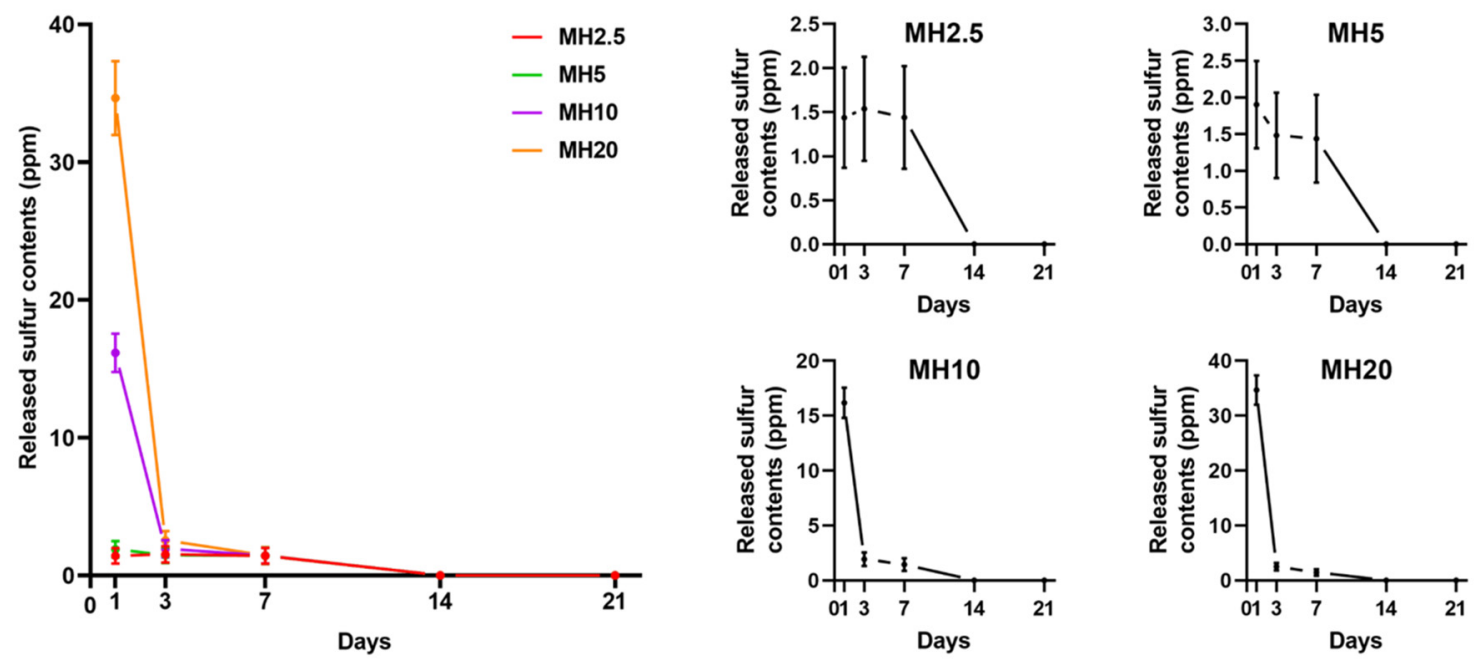

Figure 2. Sulfur ions in methylsulfonylmethane released from different $\mathrm{MH}$ groups into phosphate-buffered saline (PBS), in accordance with the day(s) of immersion $(n=9)$.

\subsection{Cell Proliferation in HAp and MH Scaffolds}

Cell proliferation and calculated proliferation rate in the HAp and MH groups from day 1 to day 3 are shown in Figure 3. The cell proliferation rate in the HAp group was not significantly different from that in the MH2.5 group $(p>0.05)$. Meanwhile, there was a significant increase in the cell proliferation rate in the MH2.5 group compared with that observed in MH5 and MH10 groups $(p<0.05)$.

(A)

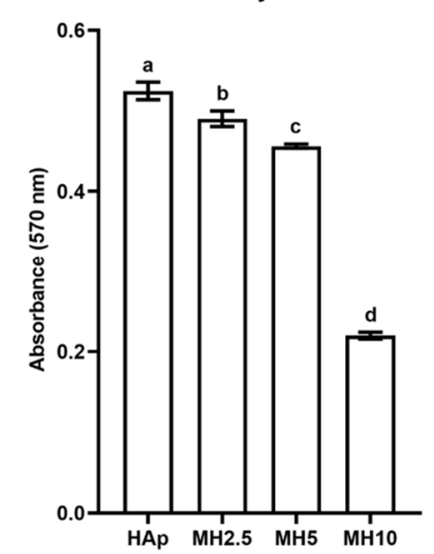

Day 3



(B) Calculated cell proliferation rate value

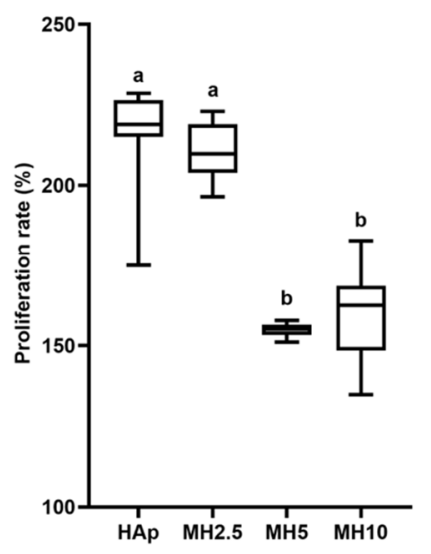

Figure 3. (A) Cell proliferation and (B) calculated cell proliferation rate in porous hydroxyapatite (HAp) and MH scaffolds. Bars labeled with different letters indicate significant differences $(n=8, p<0.05)$.

\subsection{ALP Activity in HAp and MH Scaffolds}

The ALP activity of MC3T3-E1 cells from HAp and MH groups on day 4 and day 10 was assessed. The ALP activity of HAp and MH groups was not significantly different at day 4. However, the ALP 
activity of MH2.5 group was significantly higher than that of HAp and MH5 groups at day 10 $(p<0.0001)$, while the ALP activity of MH5 was significantly higher than that of HAp (Figure 4).
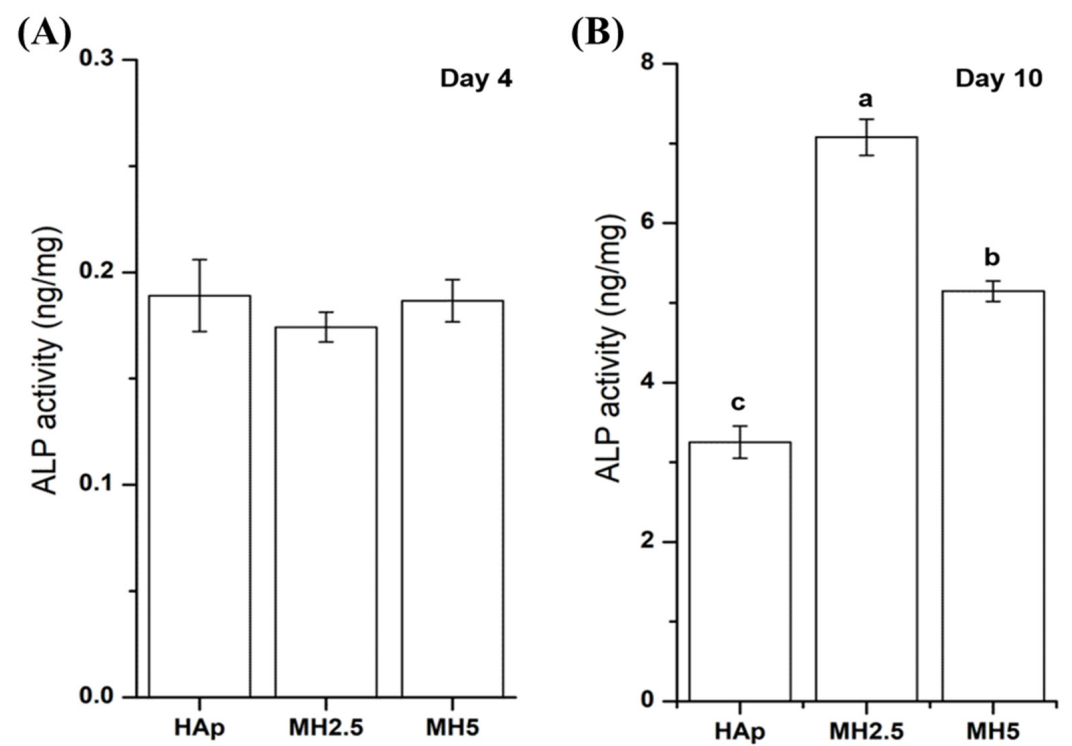

Figure 4. Alkaline phosphatase activity of MC3T3-E1 cells in porous hydroxyapatite (HAp) and MH groups after 4 days (A) and 10 days (B) for initial osteogenic differentiation. Bars labeled with different letters indicate significant differences $(n=6, p<0.05)$.

\subsection{Mineralization in HAp and MH Scaffolds}

The effect of released ions from MH groups on the mineralization of MC3T3-E1 cells over $14 \mathrm{~d}$ was investigated (Figure 5). Significantly higher levels of calcium deposition $(p<0.05)$ were observed in the MH2.5 group than in the other groups. However, mineralization in the MH5 group was significantly lower than that in HAp and MH2.5 groups $(p<0.0001)$.

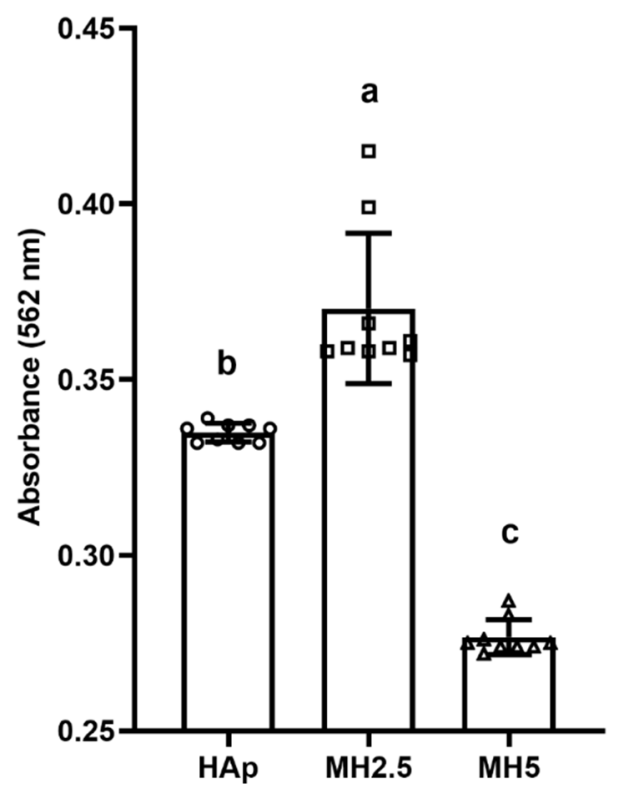

Figure 5. Quantitative analysis of calcium deposition in porous hydroxyapatite (HAp) and MH groups based on alizarin red staining for osteogenic differentiation. Bars labeled with different letters indicate significant differences $(n=9, p<0.05)$. 


\section{Discussion}

Here, we successfully coated the HAp scaffold with MSM using the dip-coating method, which demonstrated an adequate level of biocompatibility and osteoblastic proliferation and differentiation linked to potential hard tissue regeneration.

The MSM coating on HAp scaffolds maintained its porous bone-like structure (Figure 1) [11]. Moreover, we confirmed the presence of sulfur ions from MSM on the surface of MH scaffolds. The dip-coating method is recognized as an effective method for chemical coating of HAp scaffolds $[30,31]$. Hence, in this study, dip-coating was used to coat the scaffolds.

The osteoinductive effect is dependent on MSM present on the surface, and that which is released from the HAp scaffold. In Figure 2, we demonstrated that MSM release was detected in MH scaffolds. MSM was sharply released from the MH10 and MH20 groups on day 1. Burst release can be possibly attributed to the exposure of MSM present on the outer surface of the HAp scaffold. This would explain the initial release [27]. In addition, MSM was continuously released from MH scaffolds until day 7.

In Figure 2, we demonstrated that such a burst release of MSM could be cytotoxic where high doses of MSM were used (group MH20). Kim et al. reported that exposure of $>10 \mathrm{mg} / \mathrm{mL}$ MSM to cells for $24 \mathrm{~h}$ was toxic [32]. Further, Ezaki et al. reported that a high dose intake of MSM ( 0.6 and $6 \mathrm{~g} / \mathrm{kg} /$ day in rats) caused adverse effects, such as reduction of body and tissue weight [12]. Clinical trials have indicated that MSM intake causes nausea, diarrhea, headache, and eye irritation in some patients $[33,34]$.

When a high level of MSM was released from MH scaffolds, it was evident that the cell proliferation rate would also be influenced by a certain dose of MSM (Figure 3). In groups MH5 and MH10, the level of MSM released from the MH scaffolds resulted in the inhibition of cell growth in comparison to that observed in the HAp group. These observations were in agreement with a previous report by Wang et al. in which lower bioactivity and disturbed cell proliferation were observed with $10 \mathrm{wt} . \% \mathrm{MSM}$ in electrospun poly (lactic-co-glycolic acid) fibers compared with controls [27]. A possible reason for this decrease in cell proliferation rate could be the level of sulfur present in MSM. Several studies have reported that the inhibition of cell growth was due to a high level of sulfur in MSM [35,36]. Based on the results of sulfur ion release test and cell proliferation assays, we performed cell mineralization studies with the remaining groups, excluding MH10 and MH20.

Despite cellular cytotoxicity to cells and a disturbed cellular proliferation rate at a certain level of MSM (MH2.5), that osteoinductive features of MSM were evident, as indicated by ALP activity (Figure 4) and mineralization of the preosteoblasts (Figure 5). The ALP activity of the MH2.5 group was higher than that of HAp and MH5 groups at day 10. In this result, the MH2.5 group induced the differentiation from preosteoblasts to osteoblasts. Kim et al. reported that MSM induced the expression of bone morphogenetic proteins for osteoblast differentiation in MSCs [16]. While MSM had a positive effect on osteogenic differentiation from MSCs to osteoblasts, a previous study had confirmed that MSM increased the activity of ALP and the expression of osteonectin, osteocalcin, osterix, and Runx2. Furthermore, MSM enhanced the growth hormone, which promoted Janus kinase/signal transducers and activators of transcription pathway in osteoblast differentiation [14].

Mineralization is the final stage of osteogenesis. Based on the ALP activity result, most mineralization was observed in the MH2.5 group at day 14. According to mineralization results in this study, MSM enhanced the mineralization effect from stem cells to osteoblast-like cells, as shown in stem cells from human exfoliated deciduous teeth [15]. In terms of mineralization, the main calcium component was well known to easily combine with alizarin red [37]. There is a limitation to using calcium phosphate-based materials directly in cells. However, it was suggested as an indirect method to demonstrate mineralization in this study.

Although MC3T3-E1 preosteoblasts can differentiate into osteoblasts [38], there are limitations with respect to proving their osteogenic effects using in vitro assays as a single cell line cannot completely recapitulate the clinical environment [39].

This study was a limited in vitro study that did not consider the clinical outcomes of using the MSM-coated HAp. Properties such as mechanical and physical features were not considered in 
this study, which could be a part of future studies. However, the study clearly showed possibilities of using the MSM-coated HAp, especially MH2.5 scaffolds, for improved osteoinduction in hard tissue regeneration.

\section{Conclusions}

We successfully fabricated a HAp scaffold with MSM using the dip-coating method and facilitated the use of MSM in the biomedical field. The obtained MH scaffold did not affect the porosity of the HAp scaffold. Controlled and continuous release of MSM in the MH scaffold was observed until day 7 and the bioactivity of MSM was retained. We confirmed that the MH2.5 scaffold was biocompatible, using cytotoxicity and cell proliferation assays, and that it was effective at increasing the osteogenic potential, as demonstrated by calcium deposition of MC3T3-E1 cells. Taken together, the MH2.5 scaffold can serve as a bone substitute to support the restoration of bone structure and damaged bone.

Author Contributions: Conceptualization, J.-H.R., M.-H.H. and J.-S.K.; methodology, J.-H.R., and M.-H.H.; validation, K.-M.K., H.S. and J.-S.K.; formal analysis, J.-H.R. and T.-Y.K.; investigation, J.-H.R. and T.-Y.K.; resources, H.S. and M.-H.H.; data curation, J.-H.R., M.-H.H. and J.-S.K.; writing-original draft preparation, J.-H.R.; writing-review and editing, M.-H.H. and J.-S.K.; visualization, J.-H.R., M.-H.H. and J.-S.K.; supervision, K.-M.K., H.S., M.-H.H. and J.-S.K.; project administration, H.S. and M.-H.H.; funding acquisition, H.S. and M.-H.H. All authors have read and agreed to the published version of the manuscript.

Funding: This research was supported by the Basic Science Research Program through the National Research Foundation of Korea (NRF) funded by the Ministry of Education (NRF2016R1A6A3A11932752) and the Ministry of Science and ICT for the Bioinspired Innovation Technology Development Project (NRF-2018M3C1B7021994).

Conflicts of Interest: The authors declare no conflict of interest.

\section{References}

1. Zhang, Z.P.; Hu, J.; Ma, P.X. Nanofiber-based delivery of bioactive agents and stem cells to bone sites. Adv. Drug Deliver. Rev. 2012, 64, 1129-1141. [CrossRef]

2. Calori, G.M.; Mazza, E.; Colombo, M.; Ripamonti, C. The use of bone-graft substitutes in large bone defects: Any specific needs? Injury 2011, 42, S56-S63. [CrossRef]

3. Myeroff, C.; Archdeacon, M. Autogenous Bone Graft: Donor Sites and Techniques. J. Bone Joint Surg. Am. 2011, 93, 2227-2236. [CrossRef]

4. Hoornaert, A.; Maazouz, Y.; Pastorino, D.; Aparicio, C.; de Pinieux, G.; Fellah, B.H.; Ginebra, M.P.; Layrolle, P. Vertical Bone Regeneration with Synthetic Biomimetic Calcium Phosphate onto the Calvaria of Rats. Tissue Eng. Part C Methods 2019, 25, 1-11. [CrossRef]

5. Chen, P.; Liu, L.Y.; Pan, J.Q.; Mei, J.; Li, C.R.; Zheng, Y.Y. Biomimetic composite scaffold of hydroxyapatite/gelatin-chitosan core-shell nanofibers for bone tissue engineering. Mat. Sci. Eng. C Mater. 2019, 97, 325-335. [CrossRef] [PubMed]

6. Londono-Restrepo, S.M.; Jeronimo-Cruz, R.; Milian-Malo, B.M.; Rivera-Munoz, E.M.; Rodriguez-Garcia, M.E. Effect of the Nano Crystal Size on the X-ray Diffraction Patterns of Biogenic Hydroxyapatite from Human, Bovine, and Porcine Bones. Sci. Rep. 2019, 9, 1-12. [CrossRef] [PubMed]

7. Lin, K.F.; He, S.; Song, Y.; Wang, C.M.; Gao, Y.; Li, J.Q.; Tang, P.; Wang, Z.; Bi, L.; Pei, G.X. Low-Temperature Additive Manufacturing of Biomimic Three-Dimensional Hydroxyapatite/Collagen Scaffolds for Bone Regeneration. ACS Appl. Mater. Interfaces 2016, 8, 6905-6916. [CrossRef] [PubMed]

8. Rajesh, R.; Ravichandran, Y.D. Development of new graphene oxide incorporated tricomponent scaffolds with polysaccharides and hydroxyapatite and study of their osteoconductivity on MG-63 cell line for bone tissue engineering. RSC Adv. 2015, 5, 41135-41143. [CrossRef]

9. Domingos, M.; Gloria, A.; Coelho, J.; Bartolo, P.; Ciurana, J. Three-dimensional printed bone scaffolds: The role of nano/micro-hydroxyapatite particles on the adhesion and differentiation of human mesenchymal stem cells. Proc. Inst. Mech. Eng. 2017, 231, 555-564. [CrossRef] [PubMed]

10. Cao, Q.G.; He, Z.W.; Sun, W.Q.; Fan, G.T.; Zhao, J.N.; Bao, N.R.; Ye, T.J. Improvement of calcium phosphate scaffold osteogenesis in vitro via combination of glutamate-modified BMP-2 peptides. Mat. Sci. Eng C Mater. 2019, 96, 412-418. [CrossRef] 
11. Ryu, J.H.; Kwon, J.S.; Kim, K.M.; Hong, H.J.; Koh, W.G.; Lee, J.; Lee, H.J.; Choi, H.J.; Yi, S.; Shin, H.; et al. Synergistic Effect of Porous Hydroxyapatite Scaffolds Combined with Bioactive Glass/Poly(lactic-co-glycolic acid) Composite Fibers Promotes Osteogenic Activity and Bioactivity. ACS Omega 2019, 4, 2302-2310. [CrossRef]

12. Ezaki, J.; Hashimoto, M.; Hosokawa, Y.; Ishimi, Y. Assessment of safety and efficacy of methylsulfonylmethane on bone and knee joints in osteoarthritis animal model. J. Bone Miner. Metab. 2013, 31, 16-25. [CrossRef] [PubMed]

13. Sousa-Lima, I.; Park, S.Y.; Chung, M.; Jung, H.J.; Kang, M.C.; Gaspar, J.M.; Seo, J.A.; Macedo, M.P.; Park, K.S.; Mantzoros, C.; et al. Methylsulfonylmethane (MSM), an organosulfur compound, is effective against obesity-induced metabolic disorders in mice. Metabolism 2016, 65, 1508-1521. [CrossRef] [PubMed]

14. Joung, Y.H.; Lim, E.J.; Darvin, P.; Chung, S.C.; Jang, J.W.; Park, K.D.; Lee, H.K.; Kim, H.S.; Park, T.; Yang, Y.M. MSM Enhances GH Signaling via the Jak2/STAT5b Pathway in Osteoblast-Like Cells and Osteoblast Differentiation through the Activation of STAT5b in MSCs. PLoS ONE 2012, 7, e47477. [CrossRef] [PubMed]

15. Aljohani, H.; Senbanjo, L.T.; Chellaiah, M.A. Methylsulfonylmethane increases osteogenesis and regulates the mineralization of the matrix by transglutaminase 2 in SHED cells. PLoS ONE 2019, 14, e0225598. [CrossRef] [PubMed]

16. Kim, D.N.; Joung, Y.H.; Darvin, P.; Kang, D.Y.; Sp, N.; Byun, H.J.; Cho, K.H.; Park, K.D.; Lee, H.K.; Yang, Y.M. Methylsulfonylmethane enhances BMP-2-induced osteoblast differentiation in mesenchymal stem cells. Mol. Med. Rep. 2016, 14, 460-466. [CrossRef] [PubMed]

17. Livingston, M.; Tan, A. Coating Techniques and Release Kinetics of Drug-Eluting Stents. J. Med. Devices 2016, 10, 010801. [CrossRef]

18. Mourino, V.; Boccaccini, A.R. Bone tissue engineering therapeutics: Controlled drug delivery in three-dimensional scaffolds. J. R. Soc. Interface 2010, 7, 209-227. [CrossRef]

19. Hanafy, A.; Ali, H.; Elachy, S. Dual effect biodegradable ciprofloxacin loaded implantable matrices for osteomyelitis: Controlled release and osteointegration (vol 44, pg 1023, 2018). Drug Dev. Ind. Pharm. 2018, 44, 1023-1033. [CrossRef]

20. Farzin, A.; Etesami, S.A.; Goodarzi, A.; Ai, J. A facile way for development of three-dimensional localized drug delivery system for bone tissue engineering. Mat. Sci. Eng. C Mater. 2019, 105, 110032. [CrossRef]

21. Kim, H.W.; Knowles, J.C.; Kim, H.E. Hydroxyapatite/poly(epsilon-caprolactone) composite coatings on hydroxyapatite porous bone scaffold for drug delivery. Biomaterials 2004, 25, 1279-1287. [CrossRef]

22. Banobre-Lopez, M.; Pineiro-Redondo, Y.; Sandri, M.; Tampieri, A.; De Santis, R.; Dediu, V.A.; Rivas, J. Hyperthermia Induced in Magnetic Scaffolds for Bone Tissue Engineering. IEEE Trans. Mag. 2014, 50, 1-7. [CrossRef]

23. Wildemann, B.; Bamdad, P.; Holmer, C.; Haas, N.P.; Raschke, M.; Schmidmaier, G. Local delivery of growth factors from coated titanium plates increases osteotomy healing in rats. Bone 2004, 34, 862-868. [CrossRef] [PubMed]

24. Ponader, S.; Brandt, H.; Vairaktaris, E.; von Wilmowsky, C.; Nkenke, E.; Schlegel, K.A.; Neukam, F.W.; Holst, S.; Müller, F.A.; Greil, P. In vitro response of hFOB cells to pamidronate modified sodium silicate coated cellulose scaffolds. Colloids Surface B Biointerfaces 2008, 64, 275-283. [CrossRef]

25. Bock, N.; Riminucci, A.; Dionigi, C.; Russo, A.; Tampieri, A.; Landi, E.; Goranov, V.A.; Marcacci, M.; Dediu, V. A novel route in bone tissue engineering: Magnetic biomimetic scaffolds. Acta Biomater. 2010, 6, 786-796. [CrossRef] [PubMed]

26. Salama, N.N.; El Ries, M.A.; Toubar, S.; Abd El Hamid, M.; Walash, A.I. Thermoanalytical Investigation of Some Sulfone-Containing Drugs. J. Anal. Methods Chem. 2012. [CrossRef] [PubMed]

27. Wang, Z.L.; Wang, Y.; Zhang, P.B.; Chen, X.S. Methylsulfonylmethane-loaded electrospun poly(lactide-co-glycolide) mats for cartilage tissue engineering. RSC Adv. 2015, 5, 96725-96732. [CrossRef]

28. Karadjian, M.; Essers, C.; Tsitlakidis, S.; Reible, B.; Moghaddam, A.; Boccaccini, A.; Westhauser, F. Biological Properties of Calcium Phosphate Bioactive Glass Composite Bone Substitutes: Current Experimental Evidence. Int. J. Mol. Sci. 2019, 20, 305. [CrossRef]

29. Scarano, A.; Lorusso, F.; de Oliveira, P.S.; Padmanabhan, S.K.; Licciulli, A. Hydroxyapatite Block Produced by Sponge Replica Method: Mechanical, Clinical and Histologic Observations. Materials 2019, 12, 3079. [CrossRef] 
30. Kim, H.W.; Knowles, J.C.; Kim, H.E. Development of hydroxyapatite bone scaffold for controlled drug release via poly(epsilon-caprolactone) and hydroxyapatite hybrid coatings. J. Biomed. Mater. Res. B 2004, 70b, 240-249. [CrossRef]

31. Zhu, M.; Zhang, L.X.; He, Q.J.; Zhao, J.J.; Guo, L.M.; Shi, J.L. Mesoporous bioactive glass-coated poly(L-lactic acid) scaffolds: A sustained antibiotic drug release system for bone repairing. J. Mater. Chem. 2011, 21, 1064-1072. [CrossRef]

32. Kim, Y.H.; Kim, D.H.; Lim, H.; Baek, D.Y.; Shin, H.K.; Kim, J.K. The Anti-inflammatory Effects of Methylsulfonylmethane on Lipopolysaccharide-Induced Inflammatory Responses in Murine Macrophages. Biol. Pharm. Bull. 2009, 32, 651-656. [CrossRef] [PubMed]

33. Barrager, E.; Veltmann, J.R.; Schauss, A.G.; Schiller, R.N. A multicentered, open-label trial on the safety and efficacy of methylsulfonylmethane in the treatment of seasonal allergic rhinitis. J. Altern. Complementary Med. 2002, 8, 167-173. [CrossRef] [PubMed]

34. Zhang, M.; Wong, I.G.; Gin, J.B.; Ansari, N.H. Assessment of methylsulfonylmethane as a permeability enhancer for regional EDTA chelation therapy. Drug Deliv. 2009, 16, 243-248. [CrossRef] [PubMed]

35. Lim, E.J.; Hong, D.Y.; Park, J.H.; Joung, Y.H.; Darvin, P.; Kim, S.Y.; Na, Y.M.; Hwang, T.S.; Ye, S.K.; Moon, E.S.; et al. Methylsulfonylmethane Suppresses Breast Cancer Growth by Down-Regulating STAT3 and STAT5b Pathways. PLoS ONE 2012, 7, e33361. [CrossRef] [PubMed]

36. Sp, N.; Darvin, P.; Yoo, Y.B.; Joung, Y.H.; Kang, D.Y.; Kim, D.N.; Hwang, T.S.; Kim, S.Y.; Kim, W.S.; Lee, H.K.; et al. The combination of methylsulfonylmethane and tamoxifen inhibits the Jak2/STAT5b pathway and synergistically inhibits tumor growth and metastasis in ER-positive breast cancer xenografts. BMC Cancer 2015, 15, 474. [CrossRef] [PubMed]

37. Puchtler, H.; Meloan, S.N.; Terry, M.S. On the history and mechanism of alizarin and alizarin red S stains for calcium. J. Histochem. Cytochem. 1969, 17, 110-124. [CrossRef]

38. Arriero, M.D.; Ramis, J.M.; Perello, J.; Monjo, M. Differential Response of MC3T3-E1 and Human Mesenchymal Stem Cells to Inositol Hexakisphosphate. Cell Physiol. Biochem. 2012, 30, 974-986. [CrossRef]

39. Li, W.W.; Zhang, S.K.; Liu, J.; Liu, Y.Y.; Liang, Q.W. Vitamin K2 stimulates MC3T3-E1 osteoblast differentiation and mineralization through autophagy induction. Mol. Med. Rep. 2019, 19, 3676-3684. [CrossRef]

Publisher's Note: MDPI stays neutral with regard to jurisdictional claims in published maps and institutional affiliations.

(C) 2020 by the authors. Licensee MDPI, Basel, Switzerland. This article is an open access article distributed under the terms and conditions of the Creative Commons Attribution (CC BY) license (http://creativecommons.org/licenses/by/4.0/). 